\title{
Surveillance and Testing for Middle East Respiratory Syndrome Coronavirus, Saudi Arabia, April 2015-February 2016
}

\begin{abstract}
Abdulaziz A. Bin Saeed, Glen R. Abedi, Abdullah G. Alzahrani, lyad Salameh, Fatima Abdirizak, Raafat Alhakeem, Homoud Algarni, Osman A. El Nil, Mutaz Mohammed, Abdullah M. Assiri, Hail M. Alabdely, John T. Watson, Susan I. Gerber

Saudi Arabia has reported $>80 \%$ of the Middle East respiratory syndrome coronavirus (MERS-CoV) cases worldwide. During April 2015-February 2016, Saudi Arabia identified and tested 57,363 persons (18.4/10,000 residents) with suspected MERS-CoV infection; $384(0.7 \%)$ tested positive. Robust, extensive, and timely surveillance is critical for limiting virus transmission.
\end{abstract}

$\mathrm{M}$ iddle East respiratory syndrome (MERS) coronavirus $(\mathrm{CoV})$ causes severe respiratory illness in humans, with death occurring in $>35 \%$ of reported cases (1). MERS has been documented among persons with close contact with known case-patients in healthcare (2) and household (3) settings and among persons with recent contact with dromedaries (4). Proper clinical management of persons with suspected MERS-CoV infection who seek care in a healthcare setting relies upon adherence to recommended infection-control precautions (5), which in turn depends upon the early recognition of cases.

The International Health Regulations Emergency Committee of the World Health Organization reported that data sharing for this disease, including sharing of surveillance results, "remains limited and has fallen short of expectations" (6). To determine the extent of MERS surveillance in Saudi Arabia, we reviewed electronic surveillance data collected during April 1, 2015-February 1, 2016, to describe trends in surveillance for MERS and to compare demographic and clinical features among persons tested.

\section{The Study}

In Saudi Arabia, persons who should be tested for MERS-CoV include suspect case-patients who meet at least 1 of 4 case

Author affiliations: Ministry of Health, Riyadh, Saudi Arabia (A.A. Bin Saeed, A.G. Alzahrani, I. Salameh, R. Alhakeem, H. Algarni, O.A. El Nil, M. Mohammed, A.M. Assiri, H.M. Alabdely); Centers for Disease Control and Prevention, Atlanta, Georgia, USA (G.R. Abedi, F. Abdirizak, J.T. Watson, S.I. Gerber).

DOI: http://dx.doi.org/10.3201/eid2304.161793 definition categories (online Technical Appendix Table, https://wwwnc.cdc.gov/EID/article/23/4/16-1793-Techapp1. pdf). In brief, the categories are persons with communityacquired pneumonia (category I); healthcare-associated pneumonia (II); symptoms after exposure to a MERS-CoV case-patient (III); or unexplained febrile illness (IV). The case definition was revised in May 2014 (7); additional refinements were made in June 2015 (8). The 2015 definition included changes to the approach for testing children $\leq 14$ years of age with nonsevere illness (testing is reserved for children with exposure to camels or camel products or to a confirmed or suspected MERS case-patient). In addition to suspected cases, testing is recommended for close contacts of persons with confirmed MERS-CoV infection, regardless of symptoms, and can also be requested at the discretion of an infectious disease consultant. Tests are performed on respiratory specimens at 5 regional laboratories using real-time PCR (9).

Since March 7, 2015, official reporting of cases referred for MERS-CoV testing in Saudi Arabia has exclusively been documented through the Health Electronic Surveillance Network (HESN). When a suspected case-patient is identified for testing, the referring hospital reports demographic and basic clinical data to HESN (Figure 1). After specimens are

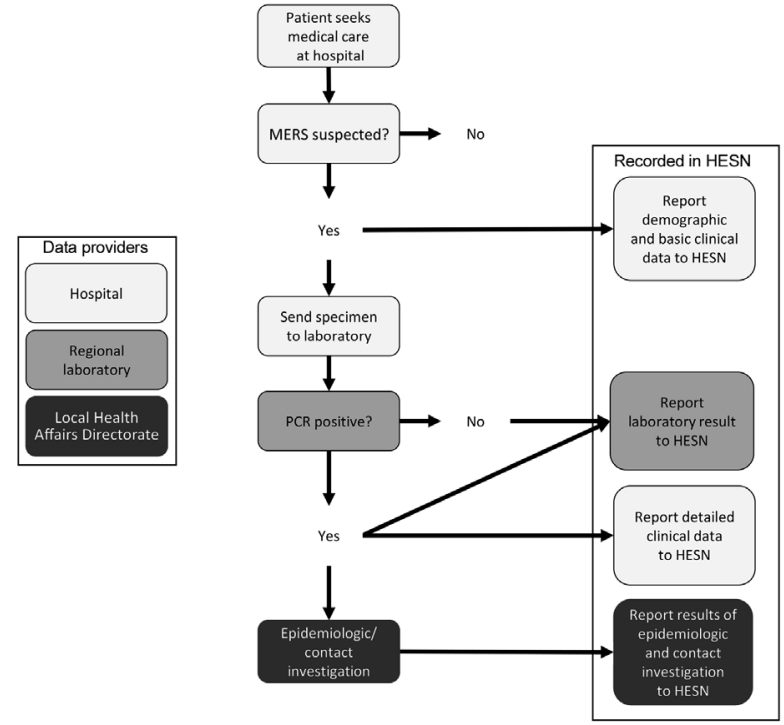

Figure 1. Reporting pathway for data regarding persons tested for Middle East respiratory syndrome coronavirus infection to the Health Electronic Surveillance Network (HESN), Saudi Arabia, 2014-2016. 
submitted and testing completed, the regional laboratory reports the result to HESN. For positive cases, the referring hospital submits additional clinical information, and the local Health Affairs Directorate (HAD) initiates an investigation of exposures and contacts. For negative test results, no further action is taken in HESN. Surveillance activities occur in each of the 20 local HADs and among Hajj pilgrims. We analyzed demographic, clinical, and laboratory data for persons reported to HESN during April 1, 2015-February 1, 2016, in aggregate and by HAD using Microsoft Excel 2013 (Microsoft Corp., Redmond, WA, USA) and SAS version 9.3 (SAS Institute, Inc., Cary, NC, USA).

A total of 57,363 suspected MERS case-patients were identified and tested during the study period; $384(0.7 \%)$ tested positive (Table 1). Among those for whom nationality and sex were known, 70.3\% were Saudi (compared with
$67.3 \%$ of the general population) and $54.3 \%$ were male. Rates of positivity among those with known age differed by age group; highest and lowest rates were among persons $50-65$ and $\leq 14$ years of age, respectively (Table 1). The month with the highest number of tested persons was November $2015(n=9,197)$ (Figure 2), and the month with the highest percentage of positive tested persons was August 2015 (3.4\% of 4,770 tested persons).

Among tested persons for whom the reason for testing was known, $89.0 \%$ met the clinical case definition for suspected MERS (Table 1). The remaining $11.0 \%$ were those recommended for testing by an infectious disease consultant and asymptomatic contacts of confirmed case-patients. More than half of those tested $(60.2 \%)$ met the category I definition (community-acquired pneumonia) for a suspected case-patient; $0.3 \%$ tested positive. The highest positivity

\begin{tabular}{|c|c|c|c|c|}
\hline Characteristic & No. $(\%)$ confirmed & No. $(\%)$ not confirmed & No. (\%) total & $\%$ Positive \\
\hline Overall & 384 & 56,979 & 57,363 & 0.7 \\
\hline \multicolumn{5}{|l|}{ Sex } \\
\hline $\mathrm{F}$ & $156(40.8)$ & $25,863(45.7)$ & $26,019(45.7)$ & 0.6 \\
\hline $\mathrm{M}$ & $226(59.2)$ & $30,718(54.3)$ & $30,944(54.3)$ & 0.7 \\
\hline Total & 382 & 56,581 & 56,963 & 0.7 \\
\hline \multicolumn{5}{|l|}{ Nationality } \\
\hline Saudi & $246(69.7)$ & $34.628(70.3)$ & $34.874(70.3)$ & 0.7 \\
\hline Non Saudi & $107(30.3)$ & $14.604(29.7)$ & $14.711(29.7)$ & 0.7 \\
\hline Total & 353 & 49,232 & 49,585 & 0.7 \\
\hline \multicolumn{5}{|l|}{ Reason for testing } \\
\hline Suspected case* & $286(77.1)$ & $47,592(89.1)$ & $47,878(89.0)$ & 0.6 \\
\hline Category I & $87(23.5)$ & $32,284(60.5)$ & $32,371(60.2)$ & 0.3 \\
\hline Category II & $67(18.1)$ & $2,662(5.0)$ & $2,729(5.1)$ & 2.5 \\
\hline Category III & $107(28.8)$ & $4,669(8.7)$ & $4,776(8.9)$ & 2.2 \\
\hline Category IV & $25(6.7)$ & $7,977(14.9)$ & $8,002(14.9)$ & 0.3 \\
\hline $\begin{array}{l}\text { Recommended by infectious disease } \\
\text { consultant }\end{array}$ & $66(17.8)$ & $3,256(6.1)$ & $3,322(6.2)$ & 2.0 \\
\hline Patient asymptomatic & $19(5.1)$ & $2,555(4.8)$ & $2,574(4.8)$ & 0.7 \\
\hline Total & 371 & 53,403 & 53,774 & 0.7 \\
\hline \multicolumn{5}{|l|}{ Month of report } \\
\hline April 2015 & $10(2.6)$ & $4,953(8.7)$ & $4,963(8.7)$ & 0.2 \\
\hline May 2015 & $54(14.1)$ & $4,414(7.7)$ & $4,468(7.8)$ & 1.2 \\
\hline June 2015 & $24(6.3)$ & $3,090(5.4)$ & $3,114(5.4)$ & 0.8 \\
\hline July 2015 & $24(6.3)$ & $2,634(4.6)$ & $2,658(4.6)$ & 0.9 \\
\hline August 2015 & $160(41.7)$ & $4,610(8.1)$ & $4,770(8.3)$ & 3.4 \\
\hline September 2015 & $66(17.2)$ & $6,520(11.4)$ & $6,586(11.5)$ & 1.0 \\
\hline October 2015 & $28(7.3)$ & $7,568(13.3)$ & $7,596(13.2)$ & 0.4 \\
\hline November 2015 & $6(1.6)$ & $9,191(16.1)$ & $9,197(16.0)$ & 0.1 \\
\hline December 2015 & $5(1.3)$ & $7,280(12.8)$ & $7,285(12.7)$ & 0.1 \\
\hline January 2016 & $6(1.6)$ & $6,487(11.4)$ & $6,493(11.3)$ & 0.1 \\
\hline February 2016 & $1(0.3)$ & $232(0.4)$ & $233(0.4)$ & 0.4 \\
\hline Total & 384 & 56,979 & 57,363 & 0.7 \\
\hline \multicolumn{5}{|l|}{ Age, $y$} \\
\hline $0-14$ & $10(2.6)$ & $8,022(14.2)$ & $8,032(14.1)$ & 0.1 \\
\hline $15-34$ & $97(25.4)$ & $17,621(31.1)$ & $17,718(31.1)$ & 0.5 \\
\hline $35-49$ & $82(21.5)$ & $10,201(18.0)$ & $10,283(18.0)$ & 0.8 \\
\hline $50-65$ & $109(28.5)$ & $10,082(17.8)$ & $10,191(17.9)$ & 1.1 \\
\hline$>66$ & $84(22.0)$ & $10,692(18.9)$ & $10,776(18.9)$ & 0.8 \\
\hline $\bar{T}$ otal & 382 & 56,618 & 57,000 & \\
\hline $\begin{array}{l}{ }^{*} \text { Categories: I, acute respiratory illness with cl } \\
\text { distress syndrome); II, a hospitalized patient } \\
\text { respiratory illness within } 2 \text { weeks after exposu } \\
\text { aches, headache, diarrhea, or nausea/vomitin } \\
\text { thrombocytopenia (platelets }<150 \times 10^{9} / \mathrm{L} \text { ). De }\end{array}$ & nfirmed or probable & $\begin{array}{l}\text { Imonary parenchymal disea } \\
\text { based on clinical and radio } \\
\text { MERS-CoV; IV, unexplaine } \\
\text { Is, and leukopenia (white b } \\
\text { Ministry of Health MERS-Cc }\end{array}$ & $\begin{array}{l}\text { (pneumonia or ac } \\
\text { ical evidence; III, } \\
\text { cute febrile }\left(\geq 38^{\circ}\right. \\
\text { d cell count }<3.5 \times \\
\text { Case Definition an }\end{array}$ & $\begin{array}{l}\text { spiratory } \\
\text { or lower } \\
\text { ess, and body } \\
\text {-) and } \\
\text { veillance }\end{array}$ \\
\hline
\end{tabular}




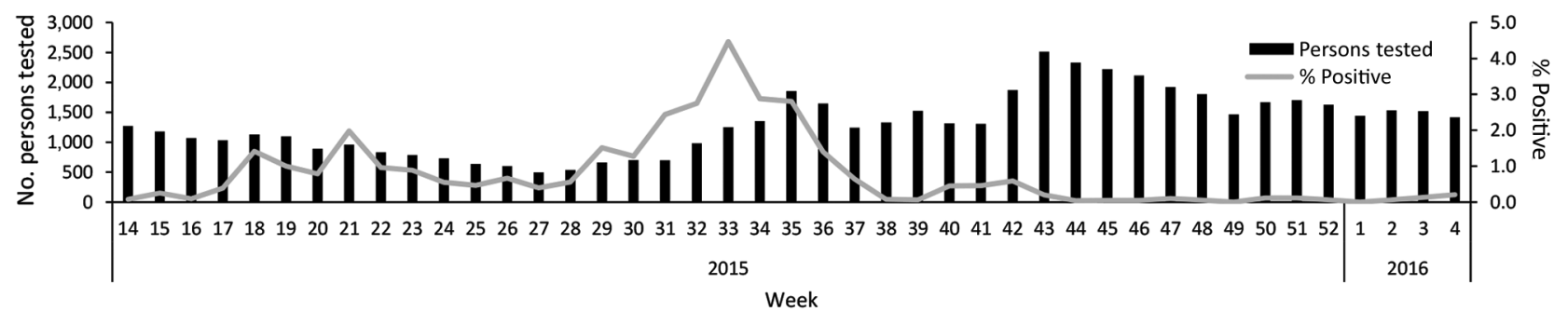

Figure 2. Number persons tested and percent positive for Middle East respiratory syndrome coronavirus, Saudi Arabia, April 1, 2015February 1, 2016.

rate, $2.5 \%$, was among persons meeting the category II definition for a suspected case-patient (healthcare-associated pneumonia). Among all persons with presumed exposure to MERS case-patients (persons meeting categories II, III and asymptomatic contacts of confirmed case-patients), the positivity rate was $1.9 \%$. Among the 185 confirmed case-patients with available occupational information, 35 $(18.9 \%)$ were healthcare workers (data not shown).

Most tested persons were reported in the course of routine surveillance through a local HAD. Nationwide, 18.4 persons/10,000 inhabitants were tested, and 1.2/100,000 were MERS-CoV-positive (10) (Table 2). Rates of testing and positivity varied by HAD; the highest testing rates were in Ahsa HAD, followed by Riyadh HAD. Najran HAD had the highest percentage of positive persons (Table 2).

In addition, surveillance during the annual Hajj pilgrimage included 888 tested persons during September 2015, representing 4.5 tested persons/10,000 among 1,952,817 pilgrims. None tested positive for MERS-CoV.
Among 8,032 children $\leq 14$ years of age, $10(0.1 \%)$ tested positive, including 5 who were $<1$ year of age. At least 7 of the 10 children were tested because of exposure to a MERS case-patient. The number of tests among children $\leq 14$ years of age temporarily dropped after the case definition revision in June 2015, which introduced more stringent criteria for testing.

\section{Conclusions}

Surveillance and testing for MERS-CoV infection is extensive and widespread in Saudi Arabia. During our study, an average of $>5,000$ persons per month were identified as being at high risk for infection due to clinical or epidemiologic criteria and were subsequently tested. MERS was first recognized in 2012, and as of November 3, 2016, Saudi Arabia has reported 80.9\% of the cases reported worldwide (11); this distinction may be partly due to the country's robust implementation of surveillance practices and the ready availability

\begin{tabular}{|c|c|c|c|c|c|}
\hline Surveillance population & Population & $\begin{array}{l}\text { No. positive/no. } \\
\text { tested }\end{array}$ & $\begin{array}{l}\text { No. tested } / 10,000 \\
\text { population }\end{array}$ & $\begin{array}{c}\text { No. confirmed } \\
\text { cases/100,000 population }\end{array}$ & $\%$ Positive \\
\hline \multicolumn{6}{|c|}{ Local Health Affairs Directorate } \\
\hline Riyadh & $7,717,467$ & $276 / 22,322$ & 28.9 & 3.6 & 1.2 \\
\hline Jeddah & $4,224,568$ & 10/6,606 & 15.6 & 0.2 & 0.2 \\
\hline Eastern & $3,019,461$ & $2 / 7,319$ & 24.2 & 0.1 & 0 \\
\hline Makkah & $2,111,127$ & $2 / 3,729$ & 17.7 & 0.1 & 0.1 \\
\hline Madinah & $2,012,749$ & $8 / 2,258$ & 11.2 & 0.4 & 0.4 \\
\hline Asir & $1,766,212$ & $6 / 1,730$ & 9.8 & 0.3 & 0.3 \\
\hline Jazan & $1,533,496$ & 0/790 & 5.2 & 0 & 0 \\
\hline Qasim & $1,370,727$ & $5 / 1,091$ & 8.0 & 0.4 & 0.5 \\
\hline Taif & $1,257,888$ & $7 / 1,866$ & 14.8 & 0.6 & 0.4 \\
\hline Ahsa & $1,193,373$ & $57 / 5,359$ & 44.9 & 4.8 & 1.1 \\
\hline Tabuk & 887,383 & 1/732 & 8.2 & 0.1 & 0.1 \\
\hline Hail & 670,468 & $0 / 685$ & 10.2 & 0 & 0 \\
\hline Najran & 568,631 & $10 / 494$ & 8.7 & 1.8 & 2.0 \\
\hline Baha & 461,360 & $0 / 184$ & 4.0 & 0 & 0 \\
\hline Hafr al-Batin & 437,349 & $0 / 145$ & 3.3 & 0 & 0 \\
\hline Bisha & 379,521 & $0 / 227$ & 6.0 & 0 & 0 \\
\hline Northern Borders & 359,297 & $0 / 240$ & 6.7 & 0 & 0 \\
\hline Jauf & 329,277 & $0 / 390$ & 11.8 & 0 & 0 \\
\hline Qunfudha & 304,392 & $0 / 183$ & 6.0 & 0 & 0 \\
\hline Qurayat & 165,629 & $0 / 122$ & 7.4 & 0 & 0 \\
\hline Total & $30,770,375$ & $384 / 56,472$ & 18.4 & 1.2 & 0.7 \\
\hline \multicolumn{6}{|l|}{ Hajj pilgrims } \\
\hline Total & $1,952,817$ & $0 / 888$ & 4.5 & 0 & 0 \\
\hline
\end{tabular}

*Population data from (10). 
of testing, which is facilitated by HESN. We found few other published descriptions of surveillance practices for MERS-CoV $(12,13)$.

Confirmed MERS case-patients represented $<1 \%$ of all tested persons in Saudi Arabia. Most tests were conducted for persons with community-acquired pneumonia, among whom the positivity rate was predictably low. Positivity rates were highest among persons tested because of presumed exposure to MERS case-patients (i.e., those tested because of healthcare-acquired pneumonia or onset of symptoms following contact with a confirmed case-patient).

Only $0.1 \%$ of children $\leq 14$ years of age tested positive for MERS-CoV; this was the lowest rate among all age groups. Most MERS-CoV-positive children $\leq 14$ years of age were tested because of high-risk exposures, not because they met clinical criteria. Although the proportion of positive tests was highest among persons $\geq 35$ years of age, the number of tests was highest among persons 18-34 years of age, perhaps because of widespread testing of healthcare workers during outbreaks.

The largest number of tests was conducted in November, coinciding with the winter respiratory virus season. In comparison, the proportion of positive tests peaked in May and August, coinciding with outbreaks that occurred in Ahsa (14) and Riyadh (15), respectively.

Our analysis had limitations. Variations were probably present in the reporting practices of the various data reporters, in the clinical diagnostic practices used across Saudi Arabia, and among investigation teams. Such variations could affect the completeness, accuracy, and timeliness of the data used for this assessment.

Surveillance and testing for MERS-CoV throughout Saudi Arabia is extensive, as documented by HESN; in a single month during this study, $>9,000$ patients at high risk for MERS were investigated. A continued robust approach to the early detection of patients with MERS is critical for the prompt implementation of infection-control precautions and the prevention of healthcare-associated transmission of MERS-CoV.

Dr. Bin Saeed served as Deputy Minister for Preventive Health at the Saudi Arabia Ministry of Health from October 2014 through October 2016 and is currently a professor of epidemiology in the Department of Family and Community Medicine at King Saud University College of Medicine in Riyadh. His research interests include epidemiologic methodologies, infection control, and outbreak investigations.

\section{References}

1. Situation update on Middle East respiratory syndrome coronavirus September-October 2016. MERS situation update 2016 Oct 2016 [cited 2016 Dec 21]. http://www.emro.who.int/images/stories/csr/ documents/MERS-CoV_Sep_October_2016.pdf?ua=1
2. Oboho IK, Tomczyk SM, Al-Asmari AM, Banjar AA, Al-Mugti H, Aloraini MS, et al. 2014 MERS-CoV outbreak in Jeddah-a link to health care facilities. N Engl J Med. 2015;372:846-54. http://dx.doi.org/10.1056/NEJMoa1408636

3. Drosten C, Meyer B, Müller MA, Corman VM, Al-Masri M, Hossain R, et al. Transmission of MERS-coronavirus in household contacts. N Engl J Med. 2014;371:828-35. http://dx.doi.org/10.1056/NEJMoa1405858

4. Alraddadi BM, Watson JT, Almarashi A, Abedi GR, Turkistani A, Sadran M, et al. Risk factors for primary Middle East respiratory syndrome coronavirus illness in humans, Saudi Arabia, 2014. Emerg Infect Dis. 2016;22:49-55. http://dx.doi.org/10.3201/ eid2201.151340

5. World Health Organization. Infection prevention and control during health care for probable or confirmed cases of novel coronavirus (nCoV) infection. Interim guidance, 6 May 2013 [cited 2016 Dec 21]. http://www.who.int/csr/disease/coronavirus_infections/ IPCnCoVguidance_06May13.pdf?ua=1

6. World Health Organization. WHO statement on the tenth meeting of the IHR Emergency Committie regarding MERS, 3 Sep 2016 [cited 2016 Nov 3]. http://www.who.int/mediacentre/news/ statements/2015/ihr-emergency-committee-mers/en/

7. Madani TA. Case definition and management of patients with MERS coronavirus in Saudi Arabia. Lancet Infect Dis. 2014;14:911-3. http://dx.doi.org/10.1016/S1473-3099(14)70918-1

8. Command and Control Center. Ministry of Health Kingdom of Saudi Arabia, Scientific Advisory Board. Infection prevention and control guidelines for Middle East respiratory syndrome coronavirus (MERS-CoV) infection. 3rd edition. June 2015 [cited 2016 Dec 21]. http://www.moh.gov.sa/en/CCC/Regulations/2015\%20update.pdf

9. World Health Organization. Laboratory testing for Middle East respiratory syndrome coronavirus (MERS-CoV). Interim guidance, updated June 2015. WHO/MERS/LAB/15.1 [cited 2016 Dec 21]. http://apps.who.int/iris/bitstream/10665/176982/1/WHO_MERS_ LAB_15.1_eng.pdf

10. Ministry of Health. Kingdom of Saudi Arabia. Statistics book. Statistical book for the year 1435. 2015 [cited 2016 Mar 23]. http://www.moh.gov.sa/en/ministry/statistics/book/pages/default.aspx

11. World Health Organization. Confirmed global cases of MERS-CoV reported to WHO as of 14 Oct 2016 [cited 2016 Oct 17]. http://www.who.int/emergencies/mers-cov/14-october-2016epicurve.png?ua $=1$

12. Al Hosani FI, Pringle K, Al Mulla M, Kim L, Pham H, Alami NN, et al. Response to emergence of Middle East respiratory syndrome coronavirus, Abu Dhabi, United Arab Emirates, 2013-2014. Emerg Infect Dis. 2016;22:1162-8. http://dx.doi.org/10.3201/ eid2207.160040

13. Schneider E, Chommanard C, Rudd J, Whitaker B, Lowe L, Gerber SI. Evaluation of patients under investigation for MERS-CoV infection, United States, January 2013-October 2014. Emerg Infect Dis. 2015;21:1220-3. http://dx.doi.org/10.3201/ eid2107.141888

14. El Bushra HE, Abdalla MN, Al Arbash H, Alshayeb Z, Al-Ali S, Latif ZA, et al. An outbreak of Middle East respiratory syndrome (MERS) due to coronavirus in Al-Ahssa region, Saudi Arabia, 2015. East Mediterr Health J. 2016;22:468-75.

15. Balkhy HH, Alenazi TH, Alshamrani MM, Baffoe-Bonnie H, Arabi Y, Hijazi R, et al. Description of a hospital outbreak of Middle East respiratory syndrome in a large tertiary care hospital in Saudi Arabia. Infect Control Hosp Epidemiol. 2016;37:1147-55. http://dx.doi.org/10.1017/ice.2016.132

Address for correspondence: Glen R. Abedi, Centers for Disease Control and Prevention; 1600 Clifton Rd NE, Mailstop A34, Atlanta, GA 303294027, USA; email: gabedi@cdc.gov 